\title{
Is there a plasma density gradient role on the generation of short-scale Farley-Buneman waves?
}

\author{
C. Haldoupis ${ }^{1}$, T. Ogawa ${ }^{2}$, K. Schlegel ${ }^{3}$, J. A. Koehler ${ }^{4}$, and T. Ono ${ }^{5}$ \\ ${ }^{1}$ Physics Department, University of Crete, Iraklion, 71003 Crete, Greece \\ ${ }^{2}$ Solar-Terrestrial Environment Laboratory, Nagoya University, Toyokawa, Aichi 442-8507, Japan \\ ${ }^{3}$ Max-Planck Institut für Sonnensystemforschung, 37191 Katlenburg-Lindau, Germany \\ ${ }^{4}$ Department of Physics and Engineering Physics, University of Saskatchewan, Saskatoon, SK, S7N-5E2, Canada \\ ${ }^{5}$ Department of Geophysics, Tohoku University, Sendai, Japan
}

Received: 19 May 2005 - Revised: 20 September 2005 - Accepted: 27 September 2005 - Published: 30 November 2005

\begin{abstract}
The physics of the unstable E-region plasma is based on the modified two stream, or Farley-Buneman, and the gradient drift instabilities. The theory combines both mechanisms into a single dispersion relation which applies for the directly generated short-scale plasma waves, known as type 1 irregularities. In the absence of a plasma gradient it is only the two stream mechanism acting which favors wave excitation if $\boldsymbol{E} \times \boldsymbol{B}$ electron drifts relative to the ions exceed a threshold slightly above the ion acoustic speed. On the other hand, the theory also predicts that a destabilizing (stabilizing) electron density gradient acts to decrease (increase) the ion acoustic threshold, and hence the wave phase velocities at threshold, depending on the gradient strength and the wavelength. Given a destabilizing plasma gradient, the threshold reduction is larger at longer than shorter wavelengths and thus the best way to test the gradient role is by simultaneous observations of type 1 waves at two or more radio backscatter frequencies. The present paper relies on dual frequency backscatter observations of $1.1 \mathrm{~m}$ and $3.1 \mathrm{~m}$ type 1 irregularities made simultaneously at $144 \mathrm{MHz}$ and $50 \mathrm{MHz}$, respectively, in mid-latitude sporadic E-layers. Using as typical plasma gradient scale lengths for destabilized sporadic E-layers those that are obtained from rocket electron density profiles, the radar observations are compared with the predictions of kinetic theory. The results suggest that the plasma density gradient effect on meter scale Farley-Buneman waves is not important. This is reinforced further by the analysis of backscatter from destabilized meteor trail plasma when very steep gradients are expected in electron density. The present findings, and more from past studies, question the electron density gradient role in the generation of short-scale plasma waves as predicted by the linear instability theory. This deserves attention and more study.
\end{abstract}

Keywords. Ionosphere (Ionospheric irregularities; Midlatitude ionosphere; Plasma waves and instabilities)

Correspondence to: C. Haldoupis

(chald@physics.uoc.gr)

\section{Introduction}

Numerous radar studies on equatorial, auroral, and midlatitude E-region plasma irregularities have led to the conviction that the operating mechanisms that destabilize the plasma are the modified two stream, or Farley-Buneman (FB), and the gradient-drift (GD) instabilities (e.g. see reviews by Fejer and Kelley, 1980; Farley, 1985; Riggin et al., 1987; Haldoupis, 1989; Sahr and Fejer, 1996; Moorcroft, 2002; and references cited therein). Through the past years, the radar experiments, which cover the HF, VHF and UHF (high, very high, and ultra high) frequency bands and thus observe only short-scale irregularities with wavelengths ranging from decameters to fractions of a meter, have identified a different role for each of the two instability mechanisms: The FB instability is considered responsible for the direct excitation of the so-called type 1 irregularities, i.e. short-scale plasma waves growing spontaneously when $\boldsymbol{E} \times \boldsymbol{B}$ electron drifts exceed a threshold that is slightly above the ion-acoustic speed. The GD instability, which can lead to direct excitation of large-scale plasma waves, is identified with the so-called type 2 irregularities which are also shortscale waves but believed to be generated indirectly through a process of turbulent cascade from long wavelength GD plasma waves. In brief, the identification of type 1 and type 2 irregularities with the FB and the GD instability mechanisms, respectively, has become a well established notion in this field of research.

On the other hand, the combined linear theory of FarleyBuneman and gradient drift (FB-GD) plasma instabilities predicts that the GD mechanism can also generate at times short-scale type 1 waves directly. According to the theory, this becomes possible if steep plasma gradients exist along the ambient electric field, even when electron drifts are below the ion acoustic velocity threshold required under gradientfree conditions. The destabilizing (or stabilizing) role of the gradient drift term on type 1 waves was pointed out first by Farley and Fejer (1975), and since then it has been taken as valid and applied extensively in numerous studies. A typical 
example that comes to mind relates to interpretations proposed for the so-called type 3 and type 4 VHF auroral echoes which exhibit type 1-like narrow Doppler spectra but peaking at velocities well below and well above the ion-acoustic speed, respectively (e.g. see a review by Moorcroft, 2002).

Despite its wide acceptance and use, it is interesting to note that the destabilizing or stabilizing effect of the gradient drift term on type 1 waves was never really proven by experiment explicitly, and the existing hints in favor are speculative and inconclusive. The main difficulty for resolving the validity of the gradient drift effects is the lack of knowledge on the driving plasma density gradients, and the considerable variability in the medium which obscures possible gradient drift contributions on measured key quantities, such as the Doppler velocity of type 1 echoes.

Based on existing experimental knowledge, we believe that the role of plasma density gradients on type 1 wave generation remains an open question. The present paper makes an effort to address this question by testing a key prediction of the linear theory, namely that a destabilizing (stabilizing) plasma gradient reduces (increases) the instability threshold, and thus the type 1 wave phase velocities at threshold, more at longer than at shorter wavelengths. To investigate this point we rely here on the observations of Haldoupis et al. (2002), obtained from a rare backscatter experiment of simultaneous type 1 echoes at two widely spaced VHF frequencies, $144 \mathrm{MHz}$ and $50 \mathrm{MHz}$. The measurements were made from the island of Crete and refer to backscatter from the mid-latitude E-region during conditions of destabilized sporadic $E\left(E_{S}\right)$ plasma, when steep plasma density gradients are believed to be present. These observations led to obtaining statistical estimates of the 1.1-m to 3.1-m phase velocity ratio for type 1 waves, which are compared here with the predictions of the kinetic FB-GD instability theory. An advantage in using mid-latitude type 1 echoes is that they occur with electric fields, close to the instability threshold, when linear theory is sensible. To substantiate the postulation that strong plasma gradients are present during conditions of type 1 irregularities, typical plasma gradient lengths are estimated from electron densities measured in situ with rockets. Also, in order to test further the validity of our findings, we search for sub-ion acoustic velocity type 1 irregularities in the Doppler spectra of meteor trail backscatter when steep plasma densities are certainly present. Finally, the significance of our findings is evaluated in the frame of existing results from past radar studies.

Next, and before presenting the experimental results, we start with a brief reference on the basics of the linear instability theory and its predictions.

\section{Linear theory predictions}

The linearized instability theory of the ionospheric E-region plasma has been presented, discussed, and applied in numerous papers (e.g. see the textbook of Kelley, 1989, and the review papers mentioned in the Introduction). In the fluid approach, the effects of the modified two stream and gradient drift (FB-GD) instability mechanisms are mathematically combined in the same dispersion relation, which derives from the electron and ion equations of motion and continuity. For plasma waves propagating perpendicular to the magnetic field, the solution of the dispersion equation takes the familiar form for the plasma wave frequency $\omega$ and growth rate $\gamma$ :

$\omega=\frac{\mathbf{k} \cdot \mathbf{V}_{\mathbf{d}}}{1+\psi}$

$\gamma \simeq \frac{\psi}{v_{i}(1+\psi)}\left[\left(\left(\frac{\mathbf{k} \cdot \mathbf{V}_{\mathbf{d}}}{1+\psi}\right)^{2}+\frac{v_{i} \Omega_{e} \mathbf{k} \cdot \mathbf{V}_{\mathbf{d}}}{v_{e} k\left(L_{N}\right)_{\perp}(1+\psi)}\right)-k^{2} C_{s}^{2}\right]-2 \alpha N_{e}$,

where the symbols have their usual meaning: $\mathbf{k}$ is the plasma wave vector, $v_{e, i}$ and $\Omega_{e, i}$ are the electron and ion collision and gyrofrequencies, $\psi=v_{e} v_{i} / \Omega_{e} \Omega_{i}, C_{s}$ is the ion acoustic speed, $N_{e}$ is the mean electron density and $\alpha$ is the recombination coefficient. Furthermore, $\mathbf{V}_{\mathbf{d}}$ is the relative electronion drift velocity which is taken approximately equal to the electron Hall drift $\mathbf{V}_{e}=\boldsymbol{E} \times \boldsymbol{B} / B^{2}$, and $\left(L_{N}\right)_{\perp}=N_{e} /\left(\nabla N_{e}\right)_{\perp}$ is the electron density gradient length perpendicular to $\mathbf{B}$ and parallel to $\mathbf{E}$, taken as positive if $\left(\nabla N_{e}\right)_{\perp} \cdot \mathbf{E}>0$. Note that the relations above are valid for $v_{i}>\omega \gg \gamma$, and that the stabilizing recombination term $2 \alpha N_{e}$ is negligible for shortscale plasma waves which are of interest to E-region radio backscatter studies.

As inferred from Eq. (2), an ambient electric field $\mathbf{E}$ and an electron density gradient $\nabla N_{e}$ provide the energy for destabilization, whereas ion diffusion, represented by $k^{2} C_{s}^{2}$ in Eq. (2), is responsible for stabilization. In the absence of a plasma gradient, the gradient drift term in Eq. (2) vanishes and the process reduces to the modified two stream (FB) instability. This mechanism favors direct generation of shortscale (type 1) waves, since

$\gamma \propto k^{2}\left[\left(V_{d} \cos \theta\right)^{2}-C_{s}^{2}(1+\psi)^{2}\right]$,

where $\theta=\arccos \left(\hat{k} \cdot \hat{V}_{d}\right)$. The last expression also shows that positive growth needs sizable electric fields in order for $V_{d} \cos \theta$ to exceed a threshold slightly above $C_{s}$ at optimal instability altitudes near $105 \mathrm{~km}$. If electric fields are small, then in the presence of a plasma gradient $\left(\nabla N_{e}\right)_{\perp}$ the GD term dominates, which leads to the excitation of large wavelength waves because the negative (stabilizing) ion diffusion term is proportional to $k^{2}$. It turns out that the GD mechanism generates easily large-scale waves in the E-region with wavelengths of tens to hundreds of meters (e.g. see Fejer et al., 1984). These waves cannot be detected by the radars, but apparently feed their energy to short wavelength secondary waves (type 2) through a nonlinear cascade mechanism, as formulated by Sudan's (1983) theory of E-region plasma turbulence.

It is important to stress that the fluid model is valid for wavelengths well above the ion mean free path $l_{i}=V_{t i} / v_{i}$ or the ion Larmor radius $r_{i}=V_{t i} / \Omega_{i}$, where $V_{t i}$ is the mean ion 




Fig. 1. Fluid and kinetic theory predictions of the phase velocity ratio at threshold of $1.10 \mathrm{~m}$ to $3.15 \mathrm{~m}$ FB-GD plasma waves, or $144-$ to 50 $\mathrm{MHz}$ backscatter velocity ratio of type 1 irregularities. The computations were for mid-latitude sporadic $E$ plasma at the optimal instability altitude of $105 \mathrm{~km}$. As seen, kinetic effects are quite significant. Also, the gradient-drift term prevails for plasma density gradient lengths less than a few $\mathrm{km}$.

thermal velocity. This means that at E-region heights the fluid theory is accurate for wavelengths larger than several meters. At shorter wavelengths the plasma ceases to behave as fluid because microphysical properties come into effect, e.g. electrons become less isothermal and more adiabatic, which can be accounted for only by kinetic theory. Kinetic effects become significant for short-scale type 1 waves since theory predicts a rise in the instability threshold with decreasing wavelength, for instance, Farley's (1963) kinetic theory predicted an instability threshold about $10 \%$ higher for 1-m than for 3-m plasma waves. The kinetic theory of Farley (1963) has been generalized later by Schmidt and Gary (1973) to also include a destabilizing density gradient, and was developed further for the investigation of type 1 wave properties in the equatorial and auroral electrojets (e.g. see Ossacow et al., 1975; Schlegel and St.-Maurice, 1983).

As stated in the Introduction, this work aims in testing the gradient drift instability theory predictions by using the irregularity velocity ratio of $1.10-\mathrm{m}(144 \mathrm{MHz})$ to $3.15-\mathrm{m}(50 \mathrm{MHz})$ type 1 echoes measured in the Crete dual frequency radar experiment. In order to assess the differences between the linear fluid and kinetic theory results for $1.10-\mathrm{m}$ and $3.15-\mathrm{m}$ waves we provide in Fig. 1 their phase velocity ratio at threshold as a function of the destabilizing gradient length. The fluid theory calculations were based on Eq. (2), whereas the kinetic theory ones were obtained numerically from the dispersion relation via the iterative computational procedure of Schlegel and St.-Maurice (1983). The calculations were carried out for the optimal altitude of $105 \mathrm{~km}$ using typical E-region plasma parameters, a magnetic field $\mathrm{B}=4.3 \times 10^{-5} \mathrm{~T}$ corresponding to the midlatitude location of the Crete radar experiment, and a mean ionic mass $m_{i}=43 \mathrm{AMU}$ as representative of the sporadic $E$ metallic ion population. Inspection of Fig. 1 suggests that the kinetic effects are important for the purpose of our study, thus the radar observations must be compared to the kinetic and not the fluid model. Also, Fig. 1 shows that gradient drift contributions become significant if destabilizing gradient lengths $\left(L_{N}\right)_{\perp}$ are less than a few kilometers.

Finally, a few words on magnetic aspect angle effects. The magnetic aspect angle $\phi$ enters into the equations through the $\psi$ term, that is, $\psi=\left(v_{e} v_{i} / \Omega_{e} \Omega_{i}\right)\left(1+\Omega_{e}^{2} \sin ^{2} \phi / v_{e}^{2}\right)$, which becomes rather large even for small angles $\phi$ away from perpendicularity. At the instability threshold, however, it turns out that the phase velocities of the plasma waves computed from Eq. (2) are not dependent on aspect angle (see also Farley and Fejer, 1975). On the other hand, a small aspect angle, say 0.5 to 1.0 degrees, can increase considerably the electronion drift velocity required for plasma destabilization.

\section{Evidence for steep plasma gradients in sporadic $E$}

Numerous studies indicate the presence of steep plasma density gradients, both vertical and horizontal, during unstable sporadic $E$ plasma conditions. These gradients can have significant components perpendicular to the magnetic field which, in accord with the theory just outlined, can act to destabilize the plasma at short wavelengths. Since here we deal with sporadic E-layer backscatter, we examine next if 
such sharp gradients are indeed possible during mid-latitude sporadic $E$ instabilities.

High resolution ionosonde studies, coherent and incoherent scatter radar observations using also radio interferometer and imaging techniques, sounding rocket measurements, as well as scintillation studies, all suggest that nighttime $E_{s}$ is highly structured in plasma density. This is especially true during times when the plasma instability mechanisms are active, for the additional reason that plasma structuring, and thus inhomogeneities in conductivity, are necessary for polarization electric fields to set up inside $E_{s}$ patches which drive the plasma to become unstable to short-scale plasma irregularities (e.g. see Tsunoda et al., 2004). Next, we briefly refer to some of these studies.

Simultaneous and common volume ionosonde and midlatitude $50-\mathrm{MHz}$ backscatter observations by Hussey et al. (1998) showed that coherent VHF echoes always occur in connection with "spread $E_{s}$ ", caused by oblique reflections from a patchy and corrugated layer. Ogawa et al. (2002), used MU (Middle and Upper atmosphere) coherent radar and ionosonde observations from the same volume, to show that quasi-periodic $(\mathrm{QP})$ echoes associate with large differences between sporadic $E$ critical and blanketing frequencies, $f o E s-f b E s$, which implied steep electron density gradients in regions of QP occurrence. Numerous coherent backscatter observations, both at VHF and HF (e.g. see Hysell and Burcham, 2000, and many references therein), observed nearly always sharply defined echoing structures in RTI (range-time-intensity) displays which can be interpreted only in terms of a highly inhomogeneous $E_{s}$ plasma. Bourdillon et al. (1995) performed large azimuthal scans of $E_{s}$ backscatter with good angular resolution to show that the medium is dominated by dynamic plasma patches with scales ranging from a few kilometers to several tens of kilometers. More revealing of strong plasma structuring inside unstable $E_{s}$ are interferometer and imaging studies which detected unstable anisotropic patches, which led to the notion of drifting "plasma clouds" with scales from less than a kilometer to several kilometers (e.g. see Hysell et al., 2002; 2004 and references therein).

The most compelling evidence, however, on the strongly inhomogeneous nature of unstable sporadic $E$ comes from joint coherent and incoherent scatter radar (ISR) studies at Arecibo. Swartz et al. (2002) presented a dramatic event in which the ISR detected a sporadic layer that was extremely structured in plasma density, both vertically and horizontally, while it was accompanied by strong $50-\mathrm{MHz}$ coherent backscatter of both type 2 and type 1 echoes. Another remarkable example has been studied more recently by Hysell et al. (2004) using common volume coherent and incoherent scatter radar observations in Puerto Rico. The ISR observed a long-lasting dense layer between 100 and $110 \mathrm{~km}$ which shortly after sunset broke up into patches or clouds of dense plasma with sharp boundaries and became unstable to type 2 and also at times to type 1 irregularities. More examples of highly structured electron densities inside $E_{s}$ with cornerlike edges and thus very steep horizontal electron density gradients, were presented in earlier years by Miller and Smith (1975, 1978).

In addition, low elevation, quasi-periodic scintillation (QPS) events, which have been linked with sporadic $E$ plasma blobs and mid-latitude QP echoes, also favor the presence of steep gradients inside sporadic $E$. QPS events are mostly seen at low elevations during summer nighttime when $E_{s}$ plasma becomes usually unstable (e.g. see Tsunoda et al., 2004 for a discussion and references). Finally, electron density profiles measured in situ with rockets during sporadic E occurrences indicate steep vertical plasma gradients with characteristic gradient lengths less than $2 \mathrm{~km}$ and as low as $100 \mathrm{~m}$ (e.g. see Smith and Mechtly, 1972).

Despite all this evidence in favor of steep plasma gradients inside $E_{s}$, there exists no study on quantifying these gradients when $E_{s}$ plasma is destabilized. We attempt this in the following section.

\section{$4 E_{s}$ plasma gradient scale lenghts measured with rockets}

Here we use electron density profiles measured with SEEK (Sporadic E Experiment over Kyushu) I and II rocket probes to compute vertical density gradient lengths $\left(L_{N}\right)_{z}$ in unstable $E_{S}$ plasma. Then the gradient components perpendicular to $\mathbf{B}$, which are potentially GD-destabilizing, are computed from $\left(L_{N}\right)_{\perp}=\left(L_{N}\right)_{z} / \cos (I)$, where $I$ is the magnetic dip angle. SEEK I (Fukao et al., 1998) involved two separate rocket flights launched in late August 1996, while SEEK II (Yamamoto et al., 2005) also included two rockets launched in early August 2002. All four SEEK rockets were flown through the E-region at times when ground-based VHF coherent radars observed strong QP backscatter from sporadic $E$ layers located between 100 and $110 \mathrm{~km}$ at about $45^{\circ}$ magnetic dip angles (e.g. see Yamamoto et al., 1998). The measured $N_{e}$ profiles during ascent and descent are thus representative of $E_{s}$ plasma instability conditions. Furthermore, during all those flights Lungmuir probes detected elevated electric fields, which in some cases were sufficient to excite directly the modified two stream plasma instability (e.g. see Pfaff et al., 1998). For details on the SEEK electron density measurements used here, see Yamamoto et al. (1998) for SEEK I and Wakabayashi et al. (2005) for SEEK II.

To compute $\left(L_{N}\right)_{z}$ we use the method of Haldoupis et al. (2000) that was applied for the same purpose on EISCAT electron density profiles. This method is illustrated in Fig. 2 for a SEEK electron density profile between 95 and $115 \mathrm{~km}$. The solid line represents the ascend profile measured with an altitude resolution $\Delta z \simeq 400 \mathrm{~m}$ with rocket $\mathrm{S} 31$ launched at 23:34 LT on 3 August 2002. Seen there are two strong layers peaking at about $102.7 \mathrm{~km}$ and $104.6 \mathrm{~km}$ and having peak electron densities $7.9 \times 10^{4}$ and $9.4 \times 10^{4} \mathrm{~cm}^{-3}$, respectively. The vertical density gradient $d N_{e} / d z$ is positive pointing upward when the peak electron density increases with height, and negative in the opposite case, pointing downward. 


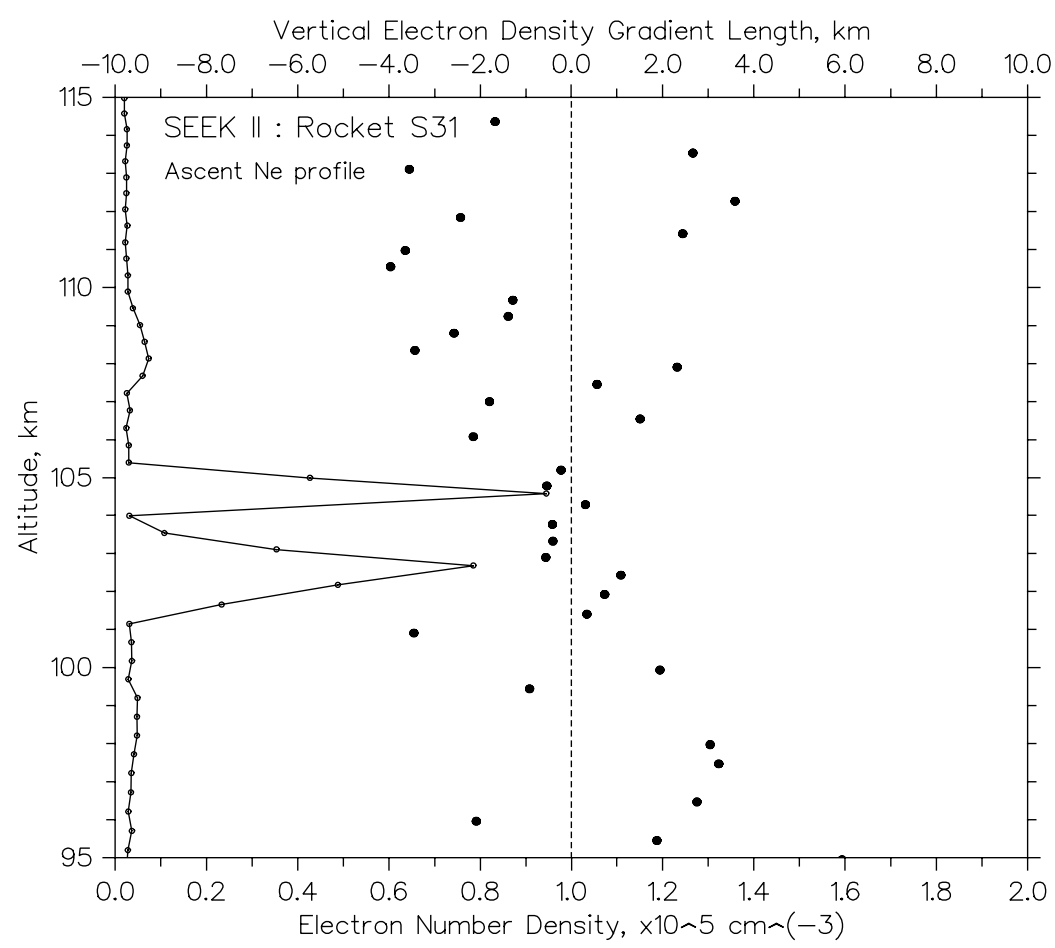

Fig. 2. Typical SEEK rocket sporadic $E$ electron density profile (solid line) and computed vertical plasma density scales (dots) expressed in kilometers. Positive (negative) gradient lengths means density gradients pointing upward (downward).

The vertical gradient scale length $\left(L_{N}\right)_{z}$ was computed from:

$\left(L_{N}\right)_{z}=\frac{N_{e}}{\left(\nabla N_{e}\right)_{z}} \simeq\left(z_{i+1}-z_{i}\right) \frac{\left[\left(N_{e}\right)_{i+1}+\left(N_{e}\right)_{i}\right] / 2}{\left(N_{e}\right)_{i+1}-\left(N_{e}\right)_{i}}$,

and assigned to the altitude $z_{i}+\frac{\Delta z}{2}$. In this way, the measured $\left(L_{N}\right)_{z}$ are expressed in $\mathrm{km}$ and plotted in Fig. 2 as solid dots. As seen, $\left(L_{N}\right)_{z}$ are positive at $E_{s}$ bottomsides and negative at topsides, taking values which close to the dense layers range between $\pm 1.5 \mathrm{~km}$. This procedure was applied for the entire data set comprised of a total of eight ascending and descending electron density profiles, all superimposed in Fig. 3. Since we are interested here in strong $E_{s}$ only, we plot in Fig. 3 only $\left(L_{N}\right)_{z}$ if electron densities are larger than $8 \times 10^{3} \mathrm{~cm}^{-3}$. As seen, the $E_{s}$-related vertical gradient lengths are equally positive and negative, and the vast majority clusters between $\pm 1.5 \mathrm{~km}$.

Figure 4 presents statistical results which include the occurrence distributions of: a) the vertical gradient length magnitudes $\left|\left(L_{N}\right)_{z}\right|$ (top-left), b) the perpendicular to the magnetic field gradient lengths $\left(L_{N}\right)_{\perp}=\left|\left(L_{N}\right)_{z}\right| / \cos (I)$ (topright), c) the $E_{S}$ altitudes (bottom-left), and d) the corresponding mean electron densities (bottom-right). Also shown in each panel of Fig. 4 are the weighted means and standard deviations of the histograms. Regarding the perpendicular gradient length $\left(L_{N}\right)_{\perp}$, which is of interest to the present study because it can play a destabilizing role for the direct generation of short-scale waves by the GD instability, the vast majority $(\sim 80 \%)$ of the estimates take up values less than about $1.5 \mathrm{~km}$, while the overall mean is somewhat below $1.0 \mathrm{~km}$. According to theory's predictions in Fig. 1, these gradients are sufficiently steep in order for the effects of the GD term in Eq. (2) on 1-m and 3-m type 1 waves to be clearly observable.

\section{144-MHz to 50-MHz type 1 velocity ratios}

The best way to test the gradient drift role on short-scale type 1 irregularities is to perform a statistical study on sporadic $E$ type 1 echoes observed simultaneously at two (or more) radar frequencies. Then, and under the postulation that the existing steep plasma gradients in $E_{S}$ act to reduce the Farley-Buneman instability threshold, the measured type 1 velocity ratios should be compared to the theoretical predictions.

A rare dual frequency radar experiment was set up in Crete, Greece during a two-month campaign in the summer of 1996, in order to measure sporadic $E$ plasma backscatter. It included the permanent 50-MHz SESCAT (Sporadic E SCATter) radar, e.g. see Haldoupis and Schlegel (1993), and a similar $144 \mathrm{MHz}$ system for simultaneous measurements. The latter had its antennas scaled exactly to the $50-\mathrm{MHz}$ arrays, in order for both systems to observe the same scattering volume in the E-region, centered at about $30.8^{\circ}$ geomagnetic latitude $(L=1.35), 52.5^{\circ}$ magnetic dip, slightly to the east of the Aegean island of Milos at about $36.7^{\circ} \mathrm{N}$ and $24.5^{\circ} \mathrm{E}$ geographic. More experimental details and an overview of the observations are given by Koehler et al. (1997). 




Fig. 3. Same as in Fig. 2, but now all eight, ascent and descent, SEEK I and II electron density profiles are superimposed. The dots denote the computed vertical plasma density scales in $\mathrm{km}$, shown only at the sporadic E-layer heights. The SEEK rockets were flown at times when the $E$ layers were unstable to GD and FB plasma irregularities.

SEEK I and SEEK II Sporadic E gradNe Measurements


Fig. 4. SEEK I and II plasma density gradient statistics during sporadic E-layer instabilities (upper panels). The lower panels show the distributions of the sporadic E-layer altitude and electron density. Here of interest is the prevailing plasma density gradients perpendicular to the magnetic field (top-right histogram) because, according to the theory, they can act to destabilize or stabilize the plasma to Farley-Buneman waves. 
Midlatitude $144 \mathrm{MHz} / 50 \mathrm{MHz}$ Type 1 Echoes
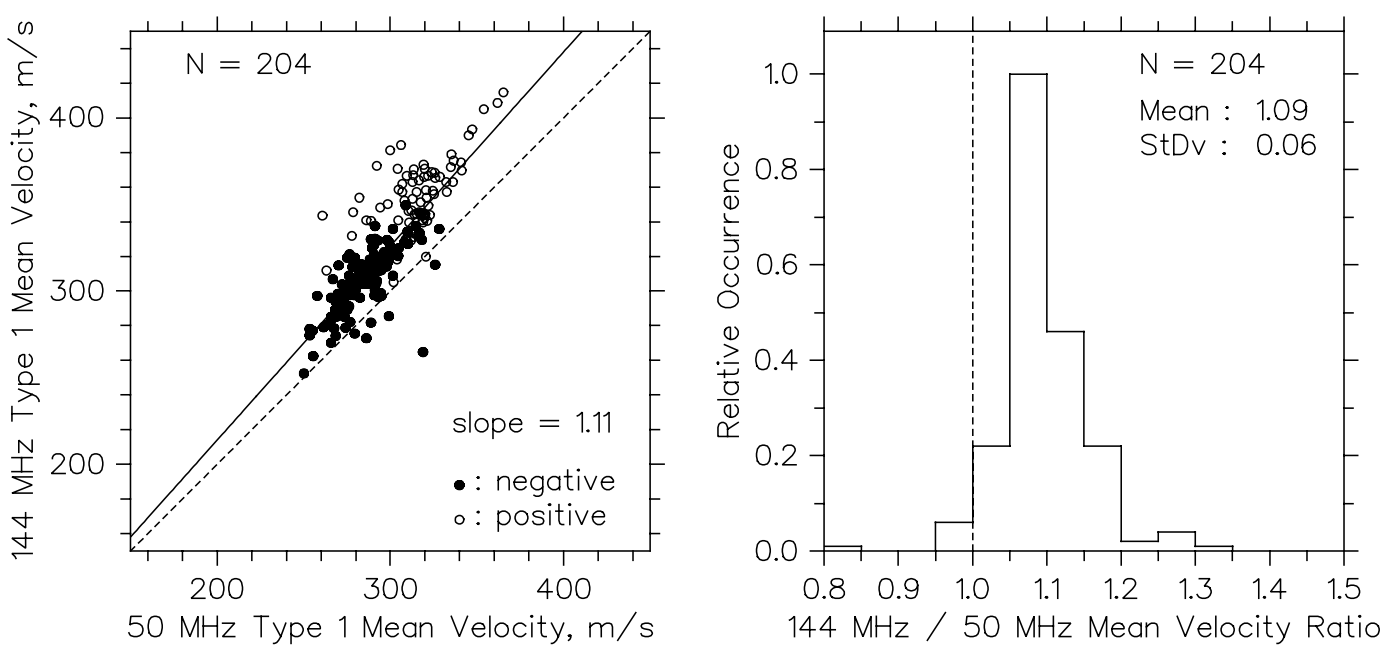

Fig. 5. Observations of type 1 mean Doppler velocities made simultaneously at 144-MHz and $50 \mathrm{MHz}$ from unstable, mid-latitude sporadic E-layer plasmas. In the left panel, the $144 \mathrm{MHz}$ velocities are plotted against those at $50 \mathrm{MHz}$ for positively and negatively Doppler-shifted type 1 echoes. As seen, there is a linear trend expressed by $V_{144} \sim 1.11 V_{50}$. The right panel shows the normalized occurrence distribution of the mean velocity ratios of $144-\mathrm{MHz}$ to $50-\mathrm{MHz}$ type 1 echoes.

This experiment verified in the most dramatic way the distinctly different character of type 1 and type 2 irregularities. The $144-\mathrm{MHz}$ type 2 echoes were totally absent during weak to moderately strong $50-\mathrm{MHz}$ signals and appeared only when the scatter at $50 \mathrm{MHz}$ was very strong, exceeding $25 \mathrm{~dB}$ above noise. This suggested a steep wave number spectrum for type 2 waves in the meter scale spectrum from 3-m to $1-\mathrm{m}$ wavelengths. In sharp contrast to type 2 , there was always a correspondence between $50-$ and $144-\mathrm{MHz}$ type 1 echoes even when the signal at $50 \mathrm{MHz}$ was only a few $\mathrm{dB}$ above noise. The sharp difference in the occurrence of the two irregularity types was indeed striking, as it has been shown and discussed in a series of two papers by Koehler et al. (1997, 1999). In fact, the clear identification of type 1 echoes at $144 \mathrm{MHz}$ helped to spot a large number of weak type 1 echoes which otherwise would have been missed or misinterpreted in the $50-\mathrm{MHz}$ backscatter alone by being imperceptible in the Doppler spectrum of the much stronger type 2 echoes seen concurrently.

A detailed analysis of the observed type 1 echo properties at $144-$ and $50-\mathrm{MHz}$ observations was carried out by Haldoupis et al. (2002). During the two months of observations, more than 20 events of type 1 echoes were identified, with lifetimes ranging between $30 \mathrm{~s}$ to a few minutes, and then their mean and peak Doppler velocities were estimated carefully from 10-second power spectra. In nearly all cases, the 144-MHz mean Doppler velocities were higher than those seen simultaneously at $50 \mathrm{MHz}$. Statistically, the measured $144-\mathrm{MHz}$ to $50-\mathrm{MHz}$ mean velocity ratios received values above unity, mostly in the range from 1.06 to 1.14 .

The left panel in Fig. 5 shows all 144- and 50-MHz type 1 velocity estimates plotted against each other. The solid dots represent negatively Doppler shifted echoes (motions away) corresponding to a total of $22 \mathrm{~min}$ of type 1 echo occurrence, whereas the open dots refer to positively shifted echoes for an overall duration of $12 \mathrm{~min}$. As seen, the velocities of $1.10-\mathrm{m}$ irregularities $(144 \mathrm{MHz})$ are steadily above the diagonal dashed line which represents the positions of equal 144and $50-\mathrm{MHz}$ mean velocity values. Also shown is a tendency for the type 1 velocity difference at $144 \mathrm{MHz}$ and $50 \mathrm{MHz}$ to increase for higher velocities, with the linear regression fit suggesting $\left(V_{m}\right)_{50} \sim 1.11\left(V_{m}\right)_{144}$.

The right panel in Fig. 5 shows the distribution of the mean velocity ratios of $144-\mathrm{MHz}(\lambda=1.10 \mathrm{~m})$ to $50-\mathrm{MHz}$ $(\lambda=3.15 \mathrm{~m})$ type 1 echoes, or approximately the phase velocity ratio of type 1 plasma waves near threshold. As seen, the great majority of the observed type 1 velocity ratios are between 1.05 and 1.15 with an overall average 1.09 , that is, the type 1 velocities at $144 \mathrm{MHz}$ are, on average, 9\% higher than those observed at $50 \mathrm{MHz}$. Remarkably, the same result was also obtained by Balsley and Farley (1971), who ran a similar dual frequency experiment at $146 \mathrm{MHz}$ and $50 \mathrm{MHz}$ in the equatorial electrojet 25 years earlier.

\section{Comparison with theory}

In their study, Haldoupis et al. (2002) used a linear kinetic model of the Farley-Buneman instability to show that the overall $9 \%$ difference in the type 1 velocities at 144- and $50-\mathrm{MHz}$ could be explained only by kinetic effects. The same conclusion was also reached by Balsley and Farley (1971) who used the predictions of Farley's (1963) kinetic theory. Here we use a linear kinetic model which also includes a destabilizing plasma density gradient, in order for 


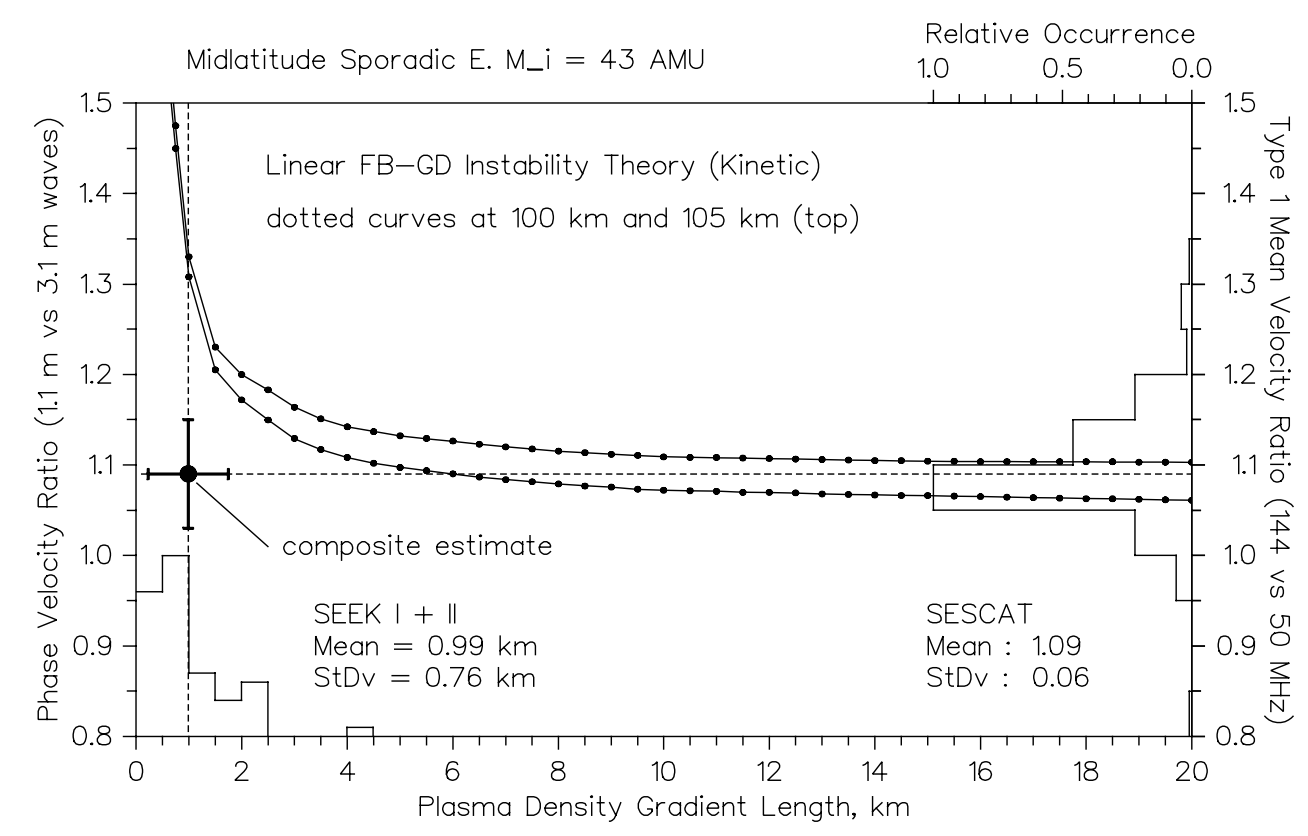

Fig. 6. The SESCAT dual frequency backscatter observations of 144- to 50-MHz type 1 velocity ratios are compared to the kinetic theory predictions for mid-latitude sporadic $E$ plasma. Also shown in the lower left corner is the distribution of destabilizing gradient lengths measured by the SEEK rockets during sporadic $E$ plasma instabilities. The composite estimate, shown to the left, is based on the distribution mean values under the assumption that the measured mean gradient lengths are representative of type 1 echo conditions. This comparison shows that the $1.10-\mathrm{m}$ to $3.15-\mathrm{m}$ type 1 velocity ratio is not affected, on average, by gradient drift instability effects.

the theoretical results to be compared with the experimental estimates. The objective is to assess if there is any significant destabilizing gradient drift contribution on type 1 waves. In this comparison we also consider the distribution of gradient length estimates obtained from all SEEK rocket electron density profiles, and assume to be, on average, representative of destabilizing plasma conditions in $E_{s}$. In addition, we adopt the widely used assumption that type 1 phase velocities remain close to the instability threshold, which at mid-latitude is very likely to happen because the driving electric fields are rarely expected to greatly exceed the instability threshold.

The theoretical and experimental results are compared in Fig. 6. The dotted curves are the kinetic theory numerical results for the $1.10-\mathrm{m}(144 \mathrm{MHz})$ to $3.15-\mathrm{m}(50 \mathrm{MHz})$ phase velocity ratio at threshold as a function of destabilizing plasma gradient length, obtained from the kinetic model used by Schlegel and St.-Maurice (1983). The lower curve corresponds to $100 \mathrm{~km}$, whereas the upper one corresponds to $105 \mathrm{~km}$ height, showing therefore the expected variations in the altitude range where the instability is expected to occur and where, as shown by the SEEK data in Fig. 4, the sporadic $E$ layers are mostly located. The theoretical curves were computed for a magnetic field $\mathrm{B}=4.3 \times 10^{-5} \mathrm{~T}$ corresponding to SESCAT's viewing location, and a mean ionic mass $M_{i}=43 \mathrm{AMU}$ which is taken as representative of sporadic $E$ metallic ions. Note that, although the choice of $M_{i}$ has a serious effect on $C_{s}$ and thus on the individual phase velocities of $1.10-\mathrm{m}$ and $3.15-\mathrm{m}$ waves, it does not greatly affect the phase velocity ratio. The curves in Fig. 6 show that the gradient drift effect on the velocity ratio $V_{1.1 \mathrm{~m}} / V_{3.1 \mathrm{~m}}$ becomes important for gradient lengths $\left(L_{N}\right)_{\perp} \leq 4-5 \mathrm{~km}$, whereas it is insignificant for $\left(L_{N}\right)_{\perp}>$ to $10 \mathrm{~km}$.

The measured velocity ratio of $144-\mathrm{MHz}(1.10 \mathrm{~m})$ to $50-\mathrm{MHz}(3.15 \mathrm{~m})$ type 1 echoes is compared to the theoretical predictions with its occurrence distribution, which is plotted in the right-hand side of Fig. 6. As seen, the vast majority (more than $80 \%$ ) of the observed $V_{144} / V_{50}$ ratios corresponds to $\left(L_{N}\right)_{\perp}>10$ to $20 \mathrm{~km}$ for which there is no theoretical gradient drift effect. On the other hand, there are only about $10 \%$ of the observed values which correspond to $\left(L_{N}\right)_{\perp}<3-5 \mathrm{~km}$ for which the ratio $V_{1.1 \mathrm{~m}} / V_{3.1} \mathrm{~m}$ is expected to be affected by the gradient drift term, in accord with the FB-GD linear instability theory. It is important to stress that for the overall mean irregularity velocity ratio of 1.09 , the theoretical predictions suggest that this mean value corresponds to gradient-free Farley-Buneman waves, as concluded by Balsley and Farley (1971) and Haldoupis et al. (2002).

The above findings are reinforced more if we take into account the gradient length distribution observed from SEEK rocket data, and assume that this is realistic during type 1 echo conditions in $E_{S}$. The observed $\left(L_{N}\right)_{\perp}$ distribution is plotted in the lower left corner of Fig. 6, having a mean of $0.99 \mathrm{~km}$ and a standard deviation of $0.76 \mathrm{~km}$. As seen, the vast majority of the observed $\left(L_{N}\right)_{\perp}$ are below about $2 \mathrm{~km}$, and, as shown in Fig. 6, these values are associated with $V_{1.1 \mathrm{~m}} / V_{3.1 \mathrm{~m}}$ phase velocity ratios greater than 1.20 , which are not measured by the dual frequency radar experiment. 
SESCAT Doppler Spectra Y: $2003 \mathrm{M}: 11 \quad \mathrm{D}: 12$

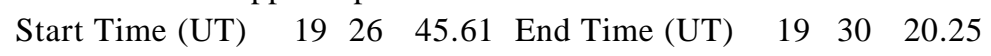

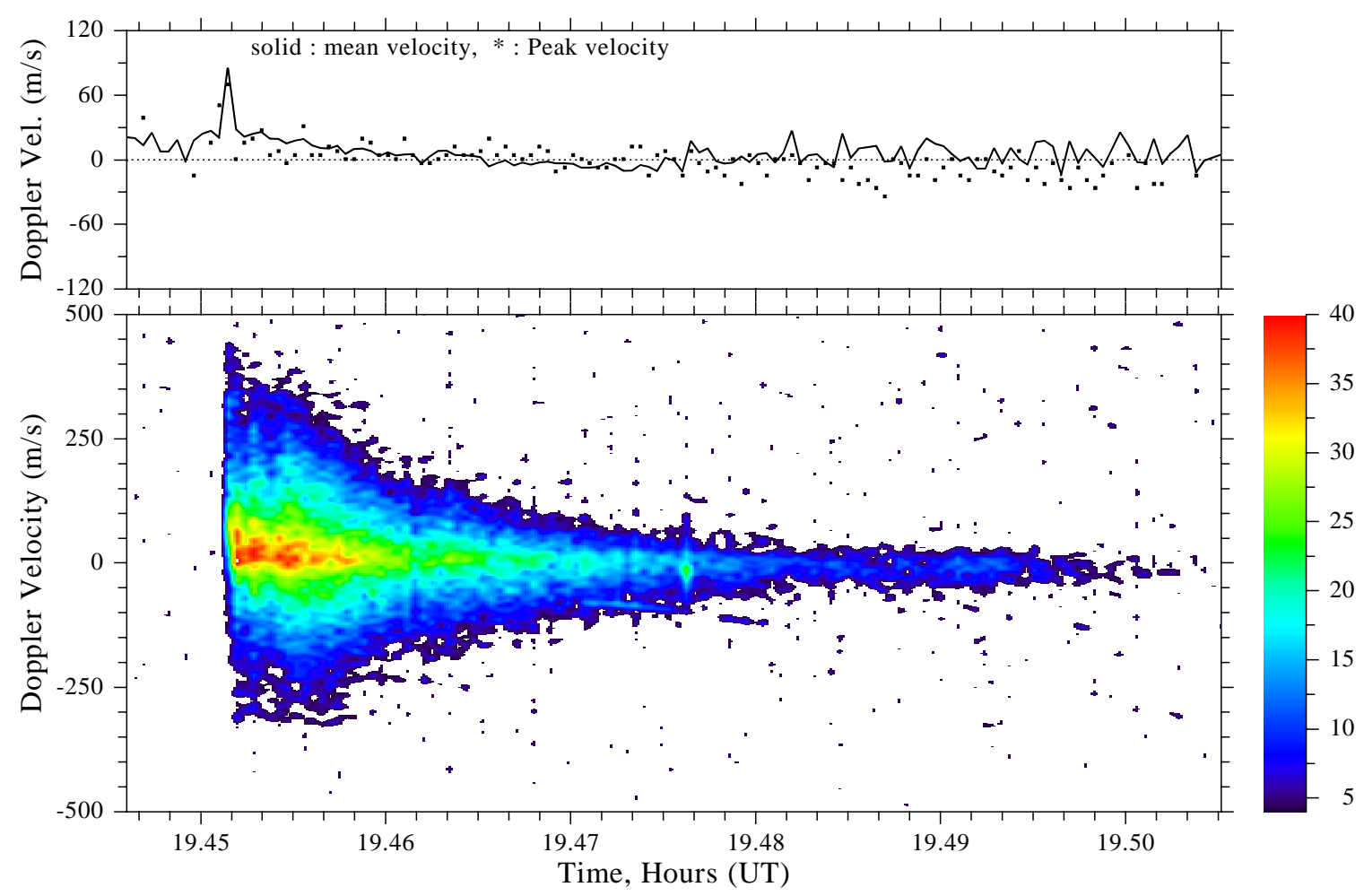

Fig. 7. A typical 50-MHz Doppler spectrogram of meteor-induced backscatter (MIB). It is characterized by an abrupt onset, and large intensities, velocities and spectrum broadening at onset. These echoes, which have lifetimes from several seconds to a few minutes, have Doppler spectra similar to those of type 2 irregularities. Although during MIB there must be very steep plasma gradients present, there is no evidence that these reduce the threshold for excitation of FB (type 1) irregularities, as predicted by theory.

Finally, if we combine the mean values and standard deviations of the observed $\left(L_{N}\right)_{\perp}$ and $V_{144} / V_{50}$ occurrence distributions, then the composite estimate is seen in Fig. 6 to be located well below the theoretical predictions.

The comparisons above show that the overwhelming majority of the dual frequency type 1 radar observations, backed also by independent estimates of destabilizing plasma gradient lengths, suggest no significant gradient drift effects on instability threshold reduction, as predicted by the linear instability theory. Although our analysis cannot be entirely conclusive, because there is no direct knowledge of the plasma gradients during the dual frequency radar observations of type 1 echoes, the present results provide evidence in favor of pure Farley-Buneman waves without any GD term contributions.

\section{More evidence against gradient drift effects}

To test further if there is a GD role on type 1 wave generation we consider backscatter observations which have occurred under conditions of steep plasma gradients. This refers to long-lasting meteor induced backscatter (MIB) events observed occasionally at $50 \mathrm{MHz}$. Before looking at these data, we provide first some background information on coherent backscatter echoes from meteor trails.

In addition to the specular reflections from underdense and overdense meteors, which usually last less than a second, there is also a distinct category of long-enduring meteor echoes, having lifetimes from several seconds to a few minutes. Although these were known for a long time, their identity became clear only within the last few years through observations made with VHF coherent backscatter radars at middle and equatorial latitudes by Haldoupis and Schlegel (1993), Chapin and Kudeki, (1994a, 1994b), Reddi and Nair, (1998), and Zhou et al. (2001), whereas an earlier report suggesting the same interpretation was published by Heritage et al. (1962). These meteor echoes are actually due to magnetic aspect sensitive coherent backscatter from field-aligned irregularities (FAI) induced occasionally by instabilities in dense meteor trails deposited in the lower Eregion. These non-specular meteor returns are characterized by range spreading and Doppler spectrum broadening at onset, which then decays gradually with time. The lifetimes of MIB are not defined by ambipolar diffusion but by the strength of the instability drivers, ion recombination, and possibly the trail geometry relative to the magnetic field (e.g. see Heritage et al., 1962). MIB, or non-specular meteor 




Fig. 8. Two more examples of long-lasting MIB Doppler spectrograms, but no evidence that the steep plasma gradients, which are expected to be present in MIB, lower the threshold for the FB instability.

echoes, were dealt theoretically and through numerical simulations by Oppenheim et al. 2000, 2003), who suggested that large polarization fields across the trail set up and combine with steep density gradients to initiate FB and GD instabilities which lead to FAI and plasma turbulence.

Here we use MIB events detected by SESCAT at $50 \mathrm{MHz}$ as a means of testing if there is a gradient drift effect on the direct generation of short-scale (type 1) irregularities in the trail plasma. In this way, we assume that the instability theory is valid, which requires that plasma wavelengths $\lambda \ll\left(L_{N}\right)_{\perp}$, which means that for meter wavelengths the radial trail dimensions must be several tens of meters. Since we deal here with long-lasting meteors and echoes spread in range, this condition is likely to be met after many seconds. According to Pellinen-Wannberg and Wannberg (1996), a meteor trail can reach a radial size of tens of meters after several seconds, and hundreds of meters after a few tens of seconds, in the lower E-region, and thus is capable of sustaining a population of short wavelength ion plasma waves. Although with the expansion of the trail its plasma density decreases, it still remains orders of magnitude larger than its background electron density, because recombination is relatively slow at about $100 \mathrm{~km}$ for the times scales under consideration. In turn, this implies the presence of steep plasma gradients in the expanding trail plasma, which, in combination with ambient and bipolar polarization fields, could lead to strong plasma destabilization. This is actually what has been assumed by Chapin and Kudeki (1994a, b) and Oppenheim et al. (2000), to be taking place during MIB in the magnetic equator.

During several summers of operation, SESCAT has detected many hundreds of long-lasting MIBs with lifetimes ranging from about $30 \mathrm{~s}$ to a few minutes. These are believed to originate at about 95 to $105 \mathrm{~km}$, according to the observations of Chapin and Kudeki (1994a) and Zhou et al. (2001). Since its Doppler spectra are measured with good time and frequency resolution, SESCAT identified the MIB spectra as being the same as those of regular $E_{s}$ type 2 echoes, that is, the spectra are broad and centered at small velocities, although often they are strongly skewed towards one Doppler polarity, also in line with the equatorial MIB observations of Chapin and Kudeki (1994a). The MIB Doppler spectra suggest that the same mechanism behind regular type 2 echoes is likely to also be responsible for the meteor trail plasma destabilization.

The Doppler spectrograms in Fig. 7 belong to a typical MIB event that lasted nearly $3 \mathrm{~min}$. The pronounced spectrum broadening and skewness near onset is attributed to a polarization electric field that sets in instantly, as suggested by theory and inferred by the jump in mean Doppler velocity seen in the upper panel of Fig. 7. Apparently, the polarization fields and the steep electron density gradients are the drivers behind the plasma turbulence that causes the spectral broadening which then decays exponentially with time as the free energy for instability diminishes. An example of two subsequent MIB events, each lasting for about $2.5 \mathrm{~min}$, are shown in Fig. 8. As seen again, they are characterized by type 2-like spectra, similar to those of regular $E_{s}$ echoes, caused by a process of short-scale plasma turbulence. Inspection of the spectra shows no evidence of narrow spectral components at fixed instability thresholds which could identify with type 1 echoes. This argues against a gradient drift role in lowering the threshold required for excitation of type 1 irregularities, as predicted by the linear FB-GD instability.

Are there any type 1 echoes observed in MIB? From the hundreds of MIB events inspected, we found only very few cases where a type 1 echo was also present in the spectrogram having a very weak spectral component centered at Doppler 

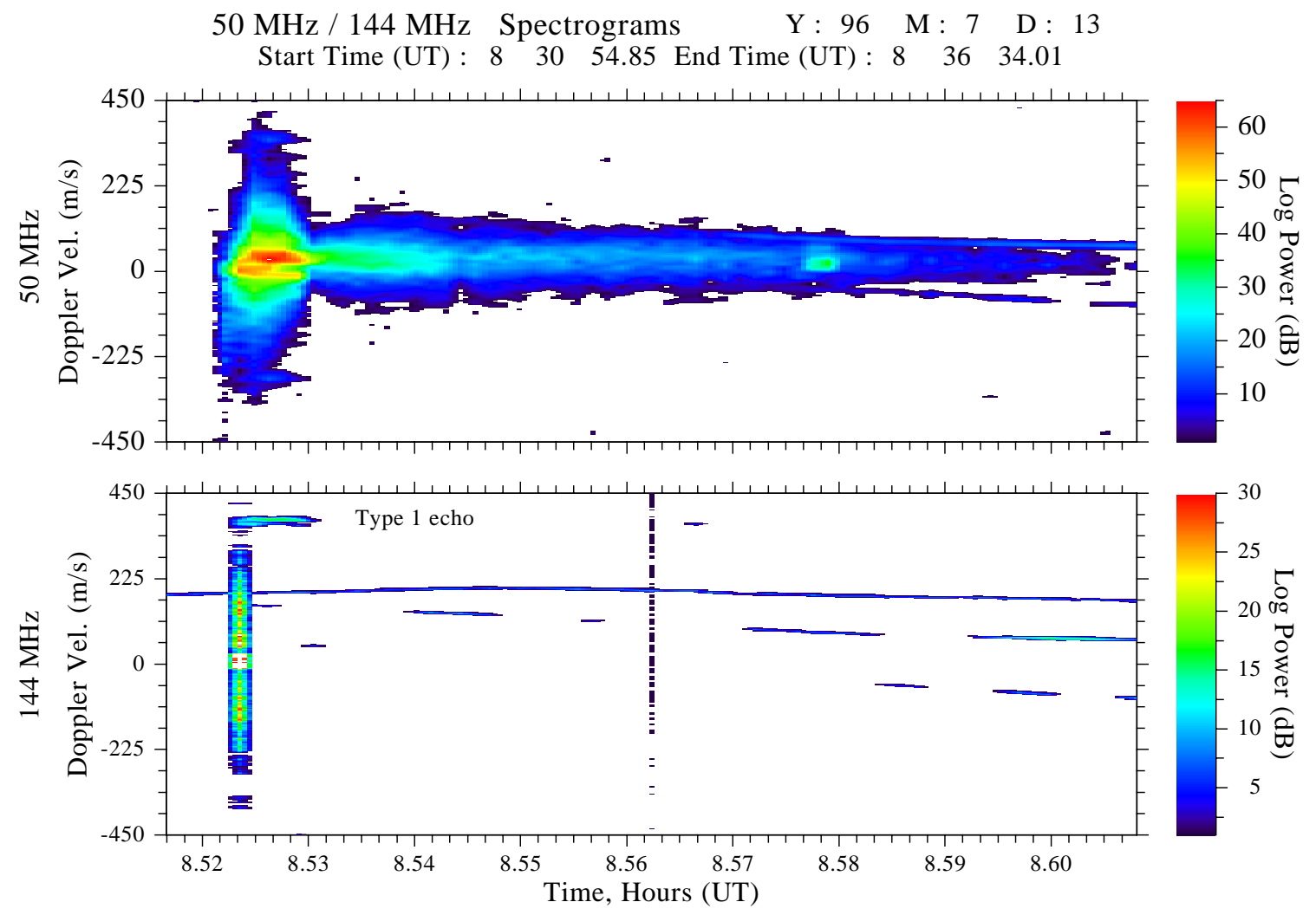

Fig. 9. A daytime, long-lasting, MIB event observed simultaneously at $50 \mathrm{MHz}$ and $144 \mathrm{MHz}$. Note that type 2-like echoes are seen only at $50 \mathrm{MHz}$, that is, at 3-m but not $1-\mathrm{m}$ plasma irregularity scales. On the other hand, the 144-MHz radar observes right after onset and for $\sim 35 \mathrm{~s}$ a weak and narrow type 1 spectral component near $+360 \mathrm{~m} / \mathrm{s}$ which corresponds to pure Farley-Buneman waves. The time axis is in decimalized hours UT $(\mathrm{LT}=\mathrm{UT}+1.6 \mathrm{~h})$, and the narrow lines are either due to antenna sidelobe airplane reflections or interference.

velocities above $300 \mathrm{~m} / \mathrm{s}$. Such a rare example was shown in the first SESCAT publication by Haldoupis and Schelegel (1993), e.g. see their Plate 2 and Fig. 9. This rarity of MIB type 1 echoes means that the enhanced electric field there seldom exceeds the two stream instability threshold of about $15 \mathrm{mV} / \mathrm{m}$. In addition, and with respect to the topic of the present study, this also means that the steep plasma gradients that must exist in the meteor plasma trails have no effect in lowering the threshold for 3-m type 1 wave excitation.

In order to reinforce the last point, and also to document an exceptional observation, we present in Fig. 9 a long-lasting MIB event that was observed simultaneously at $50 \mathrm{MHz}$ (upper panel) and $144 \mathrm{MHz}$ (lower panel). This MIB occurred during daylight and lasted for $5 \mathrm{~min}$ at $50 \mathrm{MHz}$. As seen in the $50-\mathrm{MHz}$ (upper) panel, many seconds after onset the echoes intensified enormously, reaching $65 \mathrm{~dB}$ at about $+40 \mathrm{~m} / \mathrm{s}$, which apparently led to signal distortion and generation of harmonics in the spectrum, which seem to have intensified at $\sim \pm 100 \mathrm{~Hz}( \pm 310 \mathrm{~m} / \mathrm{s})$ about the strong central peak (at $\sim+40 \mathrm{~m} / \mathrm{s}$ ), that is, the first harmonic of the power line frequency of $50 \mathrm{~Hz}$. After about $30 \mathrm{~s}$ there is a narrower and slowly decaying spectral component lasting for about $4.5 \mathrm{~min}$. On the other hand, the situation at $144 \mathrm{MHz}$, shown in the lower panel, contrasts strongly with that at $50 \mathrm{MHz}$.
The independent 144-MHz receiver observed only a strong specular component at the event's onset during the 5-s integration time of the experiment, and then missed entirely all the type 2-like echoes seen at $50 \mathrm{MHz}$ for about $5 \mathrm{~min}$. This means that the meteor trail plasma turbulence seen at $3.1 \mathrm{~m}$ $(50 \mathrm{MHz})$ is totally absent at $1.1-\mathrm{m}$ wavelength, or $144-\mathrm{MHz}$ backscatter.

Interestingly, however, there is at $144 \mathrm{MHz}$ a narrow spectral component at $+360 \mathrm{~m} / \mathrm{s}$, or $+330 \mathrm{~Hz}$ Doppler shift, which was initiated by the meteor and lived for about $35 \mathrm{~s}$. This very narrow peak is remarkably close to the daytime E-region plasma ion-acoustic speed at about $105 \mathrm{~km}$, where conditions for the FB instability are optimal, and thus it classifies as a type 1 echo at $144 \mathrm{MHz}$, produced somewhere in the meteor trail where the electric field exceeded the FB instability threshold. Note that its corresponding $50-\mathrm{MHz}$ counterpart may also be present but is not discernible, because most likely it is obscured by the $100-\mathrm{Hz}$ harmonic seen symmetrically about the strong spectral peak in the upper panel. The $144 \mathrm{MHz}$ type 1 echo near $C_{s}$, which must have occurred in the presence of very steep plasma gradients in the meteor trail, suggests that there is no theoretical GD effect on lowering the threshold for excitation of Farley-Buneman waves. 


\section{Results from past studies}

There are very few experimental indications in favor of a GD role on the direct excitation of short-scale type 1 waves. Farley and Fejer (1975) offered as indirect evidence the type 1 spectrum broadening observed in the nighttime equatorial electrojet, by attributing it to variable threshold conditions because of existing plasma density gradients, both stabilizing and destabilizing. This reasoning is interesting but the spectral variability and broadening can be attributed to a number of reasons that reflect simply the highly inhomogeneous and dynamic nature of the unstable plasma. These may include turbulence conditions that reduce the lifetime of the irregularities, and complicating bulk motions relating to larger scale plasma waves, neutral winds and tidal wind shears or gravity wave motions. In addition, one may expect variations in $C_{S}$ due to antenna beam altitude integration effects, possible spatial variations in electron temperature and/or in the mean ionic mass caused, say, by inhomogeneous metallic ion populations, and also changes in type 1 phase velocities caused by finite magnetic aspect angle effects. In view of these complexities, we believe that the variability in the Doppler spectra alone cannot be used as evidence in favor of the theoretical effects of plasma gradients on the short-scale type 1 phase velocities.

The only evidence in favor of a GD role on type 1 waves was presented by Hanuise and Crochet (1981), who ran a multi-frequency HF experiment in the equator and detected type 1 waves with wavelengths from $5 \mathrm{~m}$ to $30 \mathrm{~m}$, by using radar frequencies from about $30 \mathrm{MHz}$ to $5 \mathrm{MHz}$, respectively. They presented a limited data set showing increasingly lower type 1 Doppler velocities as they moved from higher to lower radar frequencies; these were attributed to lower instability thresholds by a destabilizing ambient plasma gradient with $L_{N}=6 \mathrm{~km}$, in line with the FB-GD linear instability theory.

There are, however, several questions concerning the interpretation of Hanuise and Crochet (1981). Their multifrequency measurements were not truly simultaneous since radar frequencies were changed manually every few minutes, and, more importantly, this study was based on few data, thus it cannot be viewed as statistical. Also, if one looks at the values of the measured type 1 velocities, e.g. see their Fig. 2, these are all higher than $350 \mathrm{~m} / \mathrm{s}$ for radar frequencies higher than about $7.5 \mathrm{MHz}$ (20-m waves) reaching $450 \mathrm{~m} / \mathrm{s}$ at about $30 \mathrm{MHz}$ (5-m waves), that is, they were not lower than the ion-acoustic speed threshold, expected to be near $360 \mathrm{~m} / \mathrm{s}$. Another important point is that Hanuise and Crochet (1981) did not consider kinetic effects in comparing their results with theory. Note that kinetic effects, which act to raise the FB instability threshold above $C_{s}$, can be significant even for wavelengths larger than $10 \mathrm{~m}$ (15-MHz radio frequencies), as demonstrated in an earlier multifrequency experiment also carried out in the equatorial electrojet by Balsley and Farley (1971). These last authors made simultaneous measurements at Jicamarca at 16,50 and $146 \mathrm{MHz}$ and found the plasmawave velocities of type 1 irregularities to be approximately proportional with ratios $0.9,1.0$ and 1.1 , respectively, and that these differences could have been accounted for only by kinetic effects in the FB instability.

Let us move now to the other end: Are there any published results which argue against a GD role on type 1 shortscale waves? The answer is yes, there exist results which indeed cast serious doubts on the GD role. The most specific example is the equatorial multifrequency study of Balsley and Farley (1971), just mentioned. Also, numerous studies have established the terms "ion acoustic echoes" and "Farley-Buneman waves" as equivalent to the "type 1 irregularities", which signifies a common practice gained through many years of research that basically argues against GD contributions in type 1 echo generation.

Type 1 echoes have been detected over a large range of radar frequencies, which, for the auroral studies, extends from 10 to $1300 \mathrm{MHz}$, e.g. see review by Moorcroft (2002), to have always a clear Doppler velocity threshold near $C_{s}$, a fact which by itself is taken as the strongest experimental proof in favor of the FB instability. The persistence of type 1 velocities near $C_{s}$ under a variety of conditions when strong electron density gradients are also expected to be present in the plasma argues against the theoretical GD term effects on type 1 waves. Also, the success of the Nielsen and Schlegel (1985) empirical law in predicting type 1 Doppler shifts in the auroral region for pure Farley-Buneman waves, under conditions when background gradients are strong most of the time (e.g. see EISCAT gradient length statistics presented by Haldoupis et al. (2000), makes the gradient drift effects on type 1 waves rather doubtful. According to recent auroral radar experiments by Hysell (personal communication), the Nielsen and Schlegel (1985) formula for pure type 1 waves is valid not only at 140 and $400 \mathrm{MHz}$, where the destabilizing/stabilizing gradient effects are anticipated by theory to be small, but also at $30 \mathrm{MHz}$. This, again, disputes the GD term effects suggested by the linear instability theory.

Finally, the strongest support against a GD role comes from many type 1 observations of HF radar aurora, that is, at frequencies where the GD term effect on lowering the FB instability threshold is expected to be most pronounced. There are several statistical HF radar Doppler studies in the aurora (e.g. Hanuise et al., 1991; Milan et al., 1997; 2001; Lacroix and Moorcroft, 2001, among several others), showing that type 1 echoes have narrow Doppler spectra centered at $C_{s}$ and thus these echoes have been interpreted as being due to pure FB waves. For example, the statistical study of Hanuise et al. (1991), which was based on a similar multifrequency experiment as the one performed ten years earlier by Hanuise and Crochet (1981) in the equator, showed that GD effects on type 1 irregularities were not important. Also, a carefully conducted Super-DARN experiment by Lacroix and Moorcroft (2001), who made observations with the radar beam direction pointing close to magnetic east along the flow direction, that is, along a direction that is most favorable for effects from both vertical and horizontal plasma gradients on type 1 waves, found no effect on the mean Doppler velocity of type 1 echoes which had their velocities always close to $C_{s}$. The auroral ion acoustic echoes seen at HF have been 
reviewed critically by Moorcroft (2002), who concluded that: "observations of type 1 echoes at HF deny the expected effects of density gradients as predicted by the linear theory of FB-GD instabilities".

\section{Summary and implications}

The aim of the present study was to investigate if there exists a plasma density gradient (GD) effect on short-scale FarleyBuneman (FB) plasma waves, in accord with the linear theory of E-region plasma instabilities. Since the theory predicts that GD effects are more severe at longer than shorter wavelengths, we tested the GD role by using simultaneous VHF backscatter observations of 1-m and 3-m type 1 waves from destabilized sporadic $E$ layers, when steep plasma density gradients are expected to be present. Estimates of the plasma gradient scale lengths in sporadic $E$ were obtained from electron density profiles measured in situ with rockets. Also, backscatter from meteor trail plasma were studied in an effort to identify type 1 waves generated at sub-ion acoustic speeds by the action of steep destabilizing plasma gradients. The experimental results were compared with the predictions of a linear kinetic model of the FB-GD instabilities. The main results are summarized as follows:

1) Regarding meter scale type 1 plasma irregularities, the gradient drift term in the dispersion relation of the linear instability theory dominates over kinetic effects only for destabilizing gradient scale lengths less than a few kilometers.

2) Many studies suggest a wealth of steep plasma density gradients under conditions of sporadic E-layer plasma instabilities. Using electron density profiles measured in situ with rockets at times when $E_{s}$ plasma becomes unstable to the GD and FB instabilities, destabilizing plasma gradient scale lengths were estimated to be less than about $2 \mathrm{~km}$, having an overall mean near $1 \mathrm{~km}$.

3) The overwhelming majority of the measured velocity ratios of $144 \mathrm{MHz}$ to $50 \mathrm{MHz}$ type 1 irregularities, or approximately the phase velocity ratios of $1.10-\mathrm{m}$ to 3.15 -m type 1 plasma waves, ranged from 1.05 to 1.14 , with a mean near 1.09 .

4) Comparison of the measured type 1 velocity ratios of $1.10-\mathrm{m}$ to $3.15-\mathrm{m}$ irregularities with the corresponding phase velocity ratios predicted by the linear kinetic theory of the FB-GD instabilities, showed that the overwhelming majority of the measured values favored pure FB waves and no GD effects.

5) Doppler spectral analysis of 50-MHz meteor-induced backscatter (MIB) echoes, which must have occurred under conditions of very steep plasma gradients, showed mostly typical type 2 echoes. This suggested no gradient-drift effects on lowering the threshold for FB (type 1) wave excitation. The very few type 1 echoes seen in MIB were due to pure FB waves, as evidenced by their characteristic Doppler velocities near the ionacoustic speed.

6) The findings of this study are in agreement with published results, arguing against a gradient drift role on type 1 echoes, as evidenced from several past studies, mostly on HF radar aurora.

The present study compiled strong experimental evidence, showing that the plasma density gradient term in the linear dispersion relation of the E-region GD-FB plasma instabilities has no real effect on the direct excitation of meter scale plasma irregularities. This implies that the modified two stream, or Farley-Bunenan, plasma instability is the only destabilizing mechanism responsible for the direct generation of short-scale type 1 waves. Therefore, the present study points to a serious discrepancy between the conventional GD-FB instability theory and the observations. The same implication has also been made by Moorcroft (2002), because a similar discrepancy was observed in HF auroral backscatter where type 1 echoes occur with velocities near the ion acoustic speed, despite the presence of destabilizing plasma density gradients.

The important implications of the present study about the absence of a destabilizing GD role refers only to type 1 waves and it does not question the role of plasma gradients on the indirect generation of type 2 irregularities, since this role has been confirmed from equatorial radar backscatter and rocket studies (e.g. see Fejer et al., 1975; Pfaff et al., 1985, 1987).

Finally, we wish to emphasize again that the present study presents strong experimental evidence showing that the gradient drift instability, as modelled by the well-known linear theory, does not lead to the direct generation of shortscale irregularities. In other words, the evidence suggests that the gradient drift instability seem to be ineffective for short-scale wave generation. The physical reason for the imposition of a lower wavelength limit for the GD instability is not known and needs to be dealt with theoretically.

Acknowledgements. One of the authors (C. H.) would like to acknowledge the support and hospitality during his stay at the SolarTerrestrial Environment Laboratory (STEL), Nagoya University, Japan, where this work was completed, and D. Hysell of Cornell University for useful discussions and suggestions as well as for his encouragement to get the present results published in the open literature.

Topical Editor M. Pinnock thanks two referees for their help in evaluating this paper.

\section{References}

Balsley, B. B. and Farley, D. T.: Radar studies of the equatorial electrojet in three frequencies, J. Geophys. Res., 76, 8341-8341, 1971.

Bourdillon, A., Haldoupis, C., and Delloue, J.: High-frequency Doppler radar observations of magnetic aspect sensitive 
irregularities in the mid-latitude $E$ region ionosphere, J. Geophys. Res., 100, 21 503-21 521, 1995.

Chapin, E. and Kudeki, E.: Plasma wave excitation on meteor trails in the equatorial electrojet, Geophys. Res. Lett., 21, 2433-1436, 1994a.

Chapin, E. and Kudeki, E.: Radar interferometric imaging studies of long-duration meteor echoes observed at Jicamarca, J. Geophys. Res., 99, 8937-8949, 1994b.

Farley, D. T.: A plasma instability resulting in field-aligned irregularities in the ionosphere, J. Geophys. Res., 68, 6083-6097, 1963.

Farley, D. T. and Fejer, B. G.: The effect of the gradient drift term on Type 1 electrojet irregularities, J. Geophys. Res., 80, 3087-3090, 1975.

Farley, D. T.: Theory of equatorial electrojet waves: New developments and current status, J. Atmos. Terr. Phys., 47, 729-744, 1985.

Fejer, B. G., Farley, D. T., Balsley, B. B., and Woodman, R. F.: Vertical structure of the VHF backscattering region in the equatorial electrojet and the gradient drift instability, J. Geophys. Res., 80, 1313-1324, 1975.

Fejer, B. G. and Kelley, M. C.: Ionospheric irregularities, Rev. Geophys., 18, 401-454, 1980.

Fejer, B. G., Providakes, J., and Farley, D. T.: Theory of plasma waves in the auroral $E$ region, J. Geophys. Res., 89, 7487-7494, 1984.

Fukao, S., Yamamoto, M., Tsunoda, R. T., Hayakawa, H., and Mukai, T.: The SEEK (Sporadic E Experiment over Kyushu), Geophys. Res. Lett., 25, 1761-1764, 1998.

Haldoupis, C.: A review of radio studies of auroral $E$ region ionospheric irregularities, Ann. Geophys., 7, 239-258, 1989.

Haldoupis, C. and Schlegel, K.: A 50-MHz radio Doppler experiment for mid-latitude $E$ region coherent backscatter studies: System description and first results, Radio Sci., 28, 959-978, 1993.

Haldoupis, C., Schlegel, K., and Hussey, G. C.: Auroral E region electron density gradients measured with EISCAT, Ann. Geophys., 18, 1172-1181, 2000,

SRef-ID: 1432-0576/ag/2000-18-1172.

Haldoupis, C., Schlegel, K., Hussey, G. C., and Koehler, J. A.: Radar observations of kinetic effects at meter scales for FarleyBuneman plasma waves, J. Geophys. Res., 107, (A10), 1272, doi:10.1029/2001JA009193, 2002.

Hanuise, C. and Crochet, M.: 5-50-m wavelenght plasma instabilities in the equatorial electrojet 2. Two-stream conditions, J. Geophys. Res., 86, 3567-3572, 1981.

Hanuise, C., Villain, J. P., Cerisier, J. C., Senior, C., Ruohoniemi, J. M., Greenwald, R. A., and Baker, K. B.: Statistical study of highlatitude $E$ region Doppler spectra obtained with the SHERPA HF radar, Ann. Geophys., 9, 273-285, 1991.

Heritage, J. L., Fay, W. J., and Bowen, E. D.: Evidence that meteor trails produce field aligned scatter at VHF, J. Geophys. Res., 67, 953-964, 1962.

Hussey, G. C., Schlegel, K., and Haldoupis, C.: Simultaneous 50$\mathrm{MHz}$ coherent backscatter and digital ionosonde observations in the mid-latitude $E$ region, J. Geophys. Res., 103, 6991-7001, 1998.

Hysell, D. L. and Burcham, J. D.: The 30-MHz radar interferometer studies of mid-latitude $E$ region irregularities, J. Geophys. Res., 105, 12 797-12 812, 2000.

Hysell, D. L., Yamamoto, M., and Fukao, S.: Imaging radar observations and theory of type I and type II quasiperiodic echoes, J. Geophys. Res., 107, 1360, 2002.
Hysell, D. L., Larsen, M. F., and Zhou, Q. H.: Common volume coherent and incoherent scatter radar observations of mid-latitude sporadic $E$ layers and QP echoes, Ann. Geophys., 22, 32773290, 2004,

\section{SRef-ID: 1432-0576/ag/2004-22-3277.}

Kelley, M. C.: The Earth's Ionosphere: Plasma Physics and Electrodynamics, Academic, San Diego, Calif., 1989.

Koehler, J. A., Haldoupis, C., Schlegel, K., and Virvilis, V.: Simultaneous observations of $E$ region coherent radar echoes at 2$\mathrm{m}$ and 6-m radio wavelengths at mid-latitude, J. Geophys. Res., 102, 17 255-17 265, 1997.

Koehler, J. A., Haldoupis, C., and Schlegel, K.: Coherent backscatter cross-section ratio measurements in the mid-latitude $E$ region ionosphere, J. Geophys. Res., 104, 4351-4359, 1999.

Lacroix, P. J. and Moorcroft, D. R.: Ion acoustic HF radar echoes at high latitudes and far ranges, J. Geophys. Res., 106, $29091-$ $29104,2001$.

Milan, S. E. and Lester, M.: A classification of spectral populations observed in $\mathrm{HF}$ radar backscatter from the $E$ region auroral electrojets, Ann. Geophys., 19, 189-204, 2001,

SRef-ID: 1432-0576/ag/2001-19-189.

Milan, S. E., Yeoman, T. K., Lester, M., Thomas, E. C., and Jones, T. B.: Initial backscatter occurrence statistics from the CUTLASS HF radars, Ann. Geophys, 15, 703-718, 1997.

Miller, K. L. and Smith, L. G.: Horizontal structure of mid-latitude sporadic $E$ layers observed by incoherent scatter radar, Radio Sci., 10, 271-276, 1975.

Miller, K. L. and Smith, L. G.: Incoherent scatter radar observations of irregular structure in mid-latitude sporadic $E$ layers, J. Geophys. Res., 83, 3761-3775, 1978.

Moorcroft, D. R.: Outstanding issues in the theory of radar aurora: Evidence from the frequency dependence of spectral characteristics, J. Geophys. Res., 107(A10), 1301, doi:10.1029/2001JA009218, 2002.

Nielsen, E. and Schlegel, K.: Coherent radar Doppler measurements and their relationship to the ionospheric electron drift velocity, J. Geophys. Res., 90, 3498-4003, 1985.

Ogawa, T., Takahashi, O., Otsuka, Y., Nozaki, K., Yamamoto, M., and Kita, K.: Simultaneous middle and upper atmosphere radar observations of turbulence and movement of mid-latitude sporadic $E$ irregularities, J. Geophys. Res., 107(A10), 1275, doi:10.1029/2001JA9000176, 2002.

Oppenheim, M. M., von Endt, A. F., and Dyrud, L. P.: Electrodynamics of meteor trail evolution in the equatorial $E$ region ionosphere, Geophys. Res. Lett., 27, 3173-3176, 2000.

Oppenheim, M. M., Dyrud, L. P., and Ray, L.: Plasma instabilties in meteor trails: Linear theory, J. Geophys. Res., 108(0), doi:10.1029/2002JA009548, 2003.

Ossakow, S. L., Papadopoulos, K., Orens, J., and Coffey, T.: Parallel propagation effects on the type 1 electrojet instability, J. Geophys. Res., 80, 141-148, 1975.

Pellinen-Wannberg, A. and Wannberg, G.: Enhanced ion-acoustic echoes from meteor trails, J. Atmos. Terr. Phys., 58, 495-506, 1996.

Pfaff, R. F., M. C. Kelley, B. G. Fejer, N. C. Maynard, L. H. Brace, B. G. Ledley, L. G. Smith, and Woodman, R. F.: Comparative in citu studies of day-time equatorial $E$ region, J. Atmos. Terr. Phys., 47, 791-811, 1985.

Pfaff, R. F., Kelley, M. C., Kudeki, E., Fejer, B. G., and Baker, K. D.: Electric field and plasma density measurements in the strongly driven daytime equatorial electrojet 1 . the undstable layer and gradient drift waves, J. Geophys. Res., 92, $13578-$ 
$13612,1987$.

Pfaff, R. F., Yamamoto, M., Marioni, P., Mori, H., and Fukao, S.: Electric field measurements above and within a sporadic- $E$ layer, Geophys. Res. Lett., 25, 1769-1772, 1998.

Riggin, D., Swartz, W. E., Providakes, J. F., and Farley, D. T.: Radar studies of long-wavelength waves associated with mid-latitude sporadic E layers, J. Geophys. Res., 91, 8011-8024, 1986.

Reddi, C. R. and Nair, S. M.: Meteor trail induced backscatter in MST radar echoes, Geophys. Res. Lett., 25, 473-476, 1998.

Sahr, J. D. and Fejer, B. G.: Auroral electrojet plasma irregularity theory and experiment: A critical review of present understanding and future directions, J. Geophys. Res., 101, 2 89-26909, 1996.

Schlegel, K. and St.-Maurice, J.-P.: Short wavelength gradient-drift waves at high latitudes, Ann. Geophys., 1, 259-264, 1983.

Schmidt, M. J. and Gary, S. P.: Density gradients and the FarleyBuneman instability, J. Geophys. Res., 78, 8261-8265, 1973.

Smith, L. G. and Mechty, E. A.: Rocket observations of sporadic $E$ layers, Radio Sci., 7, 367, 1972.

Sudan, R. N.: Unified theory of type I and type II irregularities in the equatorial electrojet, J. Geophys. Res., 88, 4853-4860, 1983.

Swartz, W. E., Collins, S. C., Kelley, M. C., Makela, J. J., Kudeki, E., Franke, S., Urbina, J., Aponte, N., Gonzalez, S., Sultzer, M. P., and Friedman, J. S.: First observations of an $F$-region turbulent upwelling coincident with severe $E$-region plasma and neutral atmosphere perturbations, J. Atmos. Solar-Terr. Phys., 64, 1545-1556, 2002.
Tsunoda, R. T., Cosgrove, R. B., and Ogawa, T.: Azimuthdependent $E_{s}$ layer instability: A missing link found, J. Geophys. Res., 109, A12303, doi:10.1029/2004JA010597, 2004.

Wakabayashi, M., Ono, T., Mori, T., and Bernhardt, P. A.: Electron density and plasma waves measurement in mid-latitude sporadic $E$ layer observed during the SEEK-2 campaign, Ann. Geophys., 23, 2335-2345, 2005,

SRef-ID: 1432-0576/ag/2005-23-2335.

Yamamoto, M., Fukao, S., Tsunoda, R. T., and Hayakawa, H.: SEEK-2 (Sporadic-E Experiment over Kyushu II): project outline and significance, Ann. Geophys., 23, 2295-2305, 2005,

SRef-ID: 1432-0576/ag/2005-23-2295.

Yamamoto, M., Istuki, T., Kishimoto, T., Tsunoda, R. T., Pfaff, R. F., and Fukao, S.: Comparison of E region electric fields observed with a sounding rocket and a Doppler radar in the SEEK campaign, Geophys. Res. Lett., 25, 1773-1776, 1998.

Yamamoto, M.-Y., Ono, T., Oya, H., Tsunoda, R. T., Larsen, M. F., Fukao, S., and Yamamoto, M.: Structures in sporadic $E$ observed with an impedance probe during the SEEK campaign: Comparisons with Neutral-wind and radar echo observations, Geophys. Res. Lett., 25, 1781-1784, 1998.

Zhou, Q. H., Mathews, J. D., and Nakamura, T.: Implications of meteor observations with the MU radar, Geophys. Res. Lett., 28, 1399-1402, 2001. 